\title{
Physical activity levels and body weight in a nationally representative sample in the European Union
}

\author{
Maria Daniel Vaz de Almeida ${ }^{1}$, Pedro Graça ${ }^{1}$, Cláudia Afonso $^{1}$, Amleto D'Amicis², \\ Raimo Lappalainen ${ }^{3}$ and Soren Damkjaer ${ }^{4}$ \\ ${ }^{1}$ Instituto Superior de Ciências da Nutrição e Alimentação da Universidade do Porto, Portugal: \\ ${ }^{2}$ Instituto Nazionale della Nutrizione, Rome, Italy: ${ }^{3}$ General Hospital Psychiatry, Tampere University Hospital, \\ PO Box 2000, FIN-33521, Tampere and Finnish Institute for Behavioural Science, Tampere, Finland: \\ ${ }^{4}$ Centre of Sport Science, Copenhagen, Denmark
}

\begin{abstract}
Objectives: The main objectives of this pan-European study were: (1) to identify different types of physical activity and the time devoted to them, (2) to assess physical activity/inactivity at work and in leisure time, and (3) to determine self-reported body weight and height.

Design and subjects: In each member state of the EU, approximately 1000 adults, aged 15 years or more, were selected to participate in an interview-assisted face-to-face questionnaire on physical activity and body weight. In each country, sample selection was quota-controlled to ensure national representativeness. Overall, 15239 subjects in the EU completed the study.

Results: On average in the EU, nearly three-quarters of the population participate in some kind of activity. In general, the highest proportions of participants were found in the Nordic countries and the lowest in the southern ones. At the European level, the five most common activities include walking, gardening, cycling, keep fit and swimming. Higher participation rates were found among men, younger subjects and those with a higher level of education. The majority of Europeans fall within the normal body mass index (BMI) range but more than one-third are overweight $(31 \%)$ or obese (10\%) and 11\% have a BMI below 20.

Conclusions: Several risk groups related to physical activity emerge from this survey: women, those with a lower level of education, older subjects, the overweight/obese and the underweight. Programmes to promote physical activity need to be tailored to the different groups identified in each country/region in order to increase adherence of non-participants and for the maintenance of those already engaged in activities.
\end{abstract}

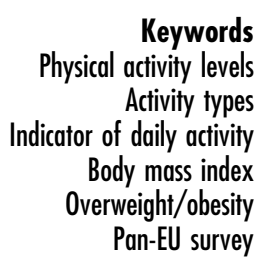

Physical activity is a complex behaviour which encompasses activity arising at work, on household tasks, self-care, transportation and discretionary leisure time, including exercise and sports ${ }^{1}$. During its long evolution, the human body has adapted to the needs of regular, moderate physical activity and a continuation of such activity is essential for its optimal functioning ${ }^{2}$. However, technological developments during the past 100 years have led to a reduction in the activity required by occupational work, transportation demands and household tasks. In recent years, the public health benefits of reducing sedentary lifestyles and promoting physical activity have become more pronounced and many reports emphasize that regular participation in moderate physical activity in an all age groups is an important component of a healthy lifestyle ${ }^{3-5}$. Epidemiological data suggest that the greatest impact of exercise is in reducing morbidity and mortality from chronic diseases such as coronary heart disease, hypertension, non-insulindependent diabetes mellitus, osteoporosis, colon cancer, anxiety and depression ${ }^{6}$. It appears that the majority of these health benefits can be obtained by performing moderate-intensity physical activities outside formal exercise programmes (for example, walking and gardening) and that the amount of activity is more important than the specific manner in which the activity is performed (i.e. mode, intensity or duration of the activity bouts $)^{5}$.

The stimulus required to produce a significant increase in aerobic capacity is usually considered to be an aerobic activity at moderate intensity for 30 minutes or $4 \mathrm{kcal}(16.8 \mathrm{~kJ}) \mathrm{kg}^{-1}$ body weight, three times or more per week ${ }^{7}$. However, this recommendation may not be optimal or minimal, and selected health benefits will require more specifity. This is the 
case for cancer prevention, for which the American Institute of Cancer Research recommends 1 hour per day of moderate physical activity plus an hour of vigorous activity each week in the cases of individuals who are relatively sedentary ${ }^{8}$.

Any physical activity, whatever its intensity, contributes to energy expenditure, thus being an important component in the prevention of weight gain and control of obesity - a condition of excess body fat that results from energy intake exceeding energy expenditure-the prevalence of which is increasing worldwide and is strongly associated with low levels of exercise $e^{9,10}$. Obesity and associated chronic noncommunicable diseases are public health problems in the EU requiring prevention and management strategies. The global epidemic of obesity is a reflection of large social, economic and cultural changes. The examination of the factors implicated in weight gain and obesity, such as physical activity and energy intake/expenditure, are necessary for the development of comprehensive public health strategies. Knowing how the different population groups distribute their time amongst different levels of activity (at work, at home and in leisure time), as well as understanding the determinants of engaging (or not engaging) in various activities, are essential in order to produce recommendations which may have a positive impact on public health across Europe.

Thus, the objectives of this study were: (1) to identify different types of activity in which EU citizens are involved and the amounts of time devoted to them, (2) to assess levels of physical activity/inactivity at work and in leisure time, and (3) to determine self-reported body weight and height.

\section{Methods}

In each member state of the EU, approximately 1000 adults, aged 15 years and upwards, were selected to participate in an interview-assisted face-to-face questionnaire on the levels of self-reported physical activity/exercise and self-assessed body weight and height. In each country, sample selection was quotacontrolled to ensure national representativeness. Overall, 15239 subjects in the EU completed the questionnaire. The information concerning the number of subjects interviewed in each member state, sample selection and questionnaire design have been described elsewhere $^{11}$. To assess activity levels, three types of questions were included:

1. Involvement in specific activities. From a list of 17 common activities/groups of activities (walking, swimming, gardening, keep fit, football, athletics, cycling, dancing, equestrian sports, etc.) subjects were asked to select those in which they participated, within a 1-week period around the time of data collection, and the weekly amount of time spent doing it. An open-ended option was also included to cover other choices. According to the recommendations for the time dedicated to physical activity/ exercise 9 , the respondents were divided into four categories: no participation, $<1.5$ hours per week, 1.5-3.5 hours per week and $>3.5$ hours per week.

2. Self-assessment of time distribution on a typical working day. There were three broad categories to choose from: sitting down, standing or walking around, and more than any of the previous.

3. Self-assessment of the amount of time spent sitting down during leisure time.

The combination of $\mathbf{2}$ with $\mathbf{3}$ allowed the calculation of an indicator of time distribution between work and leisure time (excluding participation in specific activities). Considering that in most countries subjects have five working days and two non-working days per week, the indicator was built as follows:

$$
\begin{aligned}
& \text { Indicator of daily activity }=5 \text { [variable } 1 \\
& \begin{array}{c}
+(\text { variable } 3+\text { variable } 4+\text { variable } 5) / 3 \text { ] } \\
+2 \text { variable } 2
\end{array}
\end{aligned}
$$

in which variable $1=$ number of hours sitting down in leisure time during working days; variable $2=$ number of hours sitting down in leisure time during nonworking days; variable $3=$ number of hours sitting down at work; variable $4=$ number of hours standing or walking around at work; and variable $5=$ number of hours spent in activities more demanding than in variables 3 and 4 at work. Within each variable, the amount of time was divided into three categories: I, reduced activity, II, moderate activity, and III, more than moderate activity (Table 1).

Body mass index was calculated from the subjects' information about their weight and height. Four classes of BMI were calculated according to Garrow ${ }^{12}$ : 1 , underweight $\left(\leqslant 19.99 \mathrm{~kg} \mathrm{~m}^{-2}\right) ; 2$, normal (20.00$\left.24.99 \mathrm{~kg} \mathrm{~m}^{-2}\right)$; 3, overweight (25.00-29.99 $\left.\mathrm{kg} \mathrm{m}^{-2}\right)$; and 4 , obese $\left(\geqslant 30.00 \mathrm{~kg} \mathrm{~m}^{-2}\right)$.

Average values for the EU as a whole were weighted for population size in order to take into account differences among countries. The results of individual member states were weighted for national profiles as described elsewhere ${ }^{11}$. Due to the large sample size most of the differences between groups were statistically significant. For the purpose of this paper, differences between EU groups were considered to be of greater interest in determining if programmes for physical activity promotion could be carried out at the EU or member state level, as well as for identifying specific target groups for different programmes, rather than finding if the differences were statistically 
Table 1 Various categories (I, II and III) of daily activity in leisure time and at work which were used to formulate an indicator of daily activity level for each individual

\begin{tabular}{lllll}
\hline & Variable & I & II & III \\
\hline Leisure time & 1: In working days, number of hours sitting down & $0(\geqslant 3 \mathrm{~h})$ & $1(1-3 \mathrm{~h})$ & $2(\leqslant 1 \mathrm{~h})$ \\
& 2: In non-working days, number of hours sitting down & $0(\geqslant 4 \mathrm{~h})$ & $1(2-4 \mathrm{~h})$ & $2(\leqslant 2 \mathrm{~h})$ \\
At work & 3: Number of hours sitting down & $0(\geqslant 6 \mathrm{~h})$ & $1(2-6 \mathrm{~h})$ & $2(\leqslant 2 \mathrm{~h})$ \\
& 4: Number of hours standing/walking around & $0(\leqslant 2 \mathrm{~h})$ & $1(2-6 \mathrm{~h})$ & $2(\geqslant 6 \mathrm{~h})$ \\
& 5: Number of hours doing more than that & $0(\leqslant 1 \mathrm{~h})$ & $1(1-3 \mathrm{~h})$ & $2(\geqslant 3 \mathrm{~h})$ \\
\hline
\end{tabular}

significant. Descriptive statistics rather than inferential statistics are thus presented in this paper.

\section{Results}

\section{Participation in physical activity}

On average, nearly three-quarters of the EU population participated in some kind of activity (Table 2). A wide range was found among the different member states, Portugal being the country with the lowest number of participants (40\%) in contrast to Finland where $92 \%$ of subjects were found to participate in one or other of the different activities. In general, the highest proportions of participants were found in the Nordic countries (Finland 92\% and Sweden 90\%) and the lowest in the southern ones (Spain 64\%, Italy 62\%, Greece 61\% and Portugal 40\%), Belgium (61\%) and France (65\%) (Table 2).

Table 2a Percentage of subjects in each member state involved in various activities in a 1-week interval

\begin{tabular}{|c|c|c|c|c|c|c|c|c|c|}
\hline Country & Total & Walking & Gardening & Cycling & Keep fit & Swimming & Football & Dancing & Racquet sports \\
\hline Austria & 85 & 41 & 36 & 38 & 13 & 20 & 6 & 6 & 10 \\
\hline Belgium & 61 & 26 & 14 & 19 & 10 & 10 & 6 & 5 & 7 \\
\hline Denmark & 76 & 30 & 34 & 28 & 12 & 10 & 5 & 4 & 10 \\
\hline Finland & 92 & 68 & 10 & 28 & 22 & 15 & 2 & 10 & 7 \\
\hline France & 65 & 30 & 16 & 13 & 8 & 10 & 5 & 2 & 6 \\
\hline Germany & 70 & 23 & 23 & 28 & 7 & 12 & 4 & 6 & 5 \\
\hline Greece & 61 & 24 & 10 & 2 & 15 & 4 & 5 & 3 & 2 \\
\hline Ireland & 87 & 55 & 26 & $1 \overline{5}$ & 8 & 13 & 12 & 8 & 4 \\
\hline Italy & 62 & 25 & 12 & 7 & 11 & 5 & 8 & 6 & 3 \\
\hline Luxembourg & 82 & 43 & 28 & 17 & 20 & 18 & 5 & 6 & 6 \\
\hline Netherlands & 83 & 24 & 31 & 52 & 15 & 17 & 8 & 6 & 8 \\
\hline Portugal & 40 & 20 & 3 & 3 & 4 & 4 & 10 & 2 & 1 \\
\hline Spain & 64 & 36 & 3 & 7 & 10 & 6 & 8 & $\overline{5}$ & 4 \\
\hline Sweden & 90 & 61 & 26 & 39 & 24 & 12 & 5 & 8 & 5 \\
\hline UK & 77 & 42 & 23 & 9 & 13 & 11.5 & 7 & 7 & 4 \\
\hline EU average* & 69 & 31 & 18 & 17 & 10 & 10 & 6 & 5 & 5 \\
\hline
\end{tabular}

*Weighted according to population size.

Table $\mathbf{2 b}$ Percentage of subjects in each member state involved in various activities in a 1-week interval

\begin{tabular}{|c|c|c|c|c|c|c|c|c|c|c|}
\hline Country & $\begin{array}{l}\text { Team } \\
\text { sports }\end{array}$ & Fishing & $\begin{array}{l}\text { Winter } \\
\text { sports }\end{array}$ & Athletics & $\begin{array}{c}\text { Hill } \\
\text { walking }\end{array}$ & $\begin{array}{l}\text { Martial } \\
\text { arts }\end{array}$ & Golf & $\begin{array}{l}\text { Water } \\
\text { sports }\end{array}$ & $\begin{array}{l}\text { Equestrian } \\
\text { sports }\end{array}$ & Others \\
\hline Austria & 4 & 2 & 14 & 3 & 19 & 1 & 1 & 1 & 1 & 2 \\
\hline Belgium & 3 & 2 & 2 & 2 & 1 & 2 & 1 & 1 & 1 & 2 \\
\hline Denmark & 5 & 5 & 2 & 4 & 1 & 1 & 1 & 1 & 2 & 3 \\
\hline Finland & 7 & 10 & 17 & 1 & 0 & 1 & 1 & 2 & 1 & 4 \\
\hline France & 2 & 5 & 4 & 0 & 1 & 3 & 1 & 1 & 1 & 4 \\
\hline Germany & 3 & 2 & 2 & 3 & 0 & 1 & 1 & 1 & 1 & 6 \\
\hline Greece & 8 & 4 & 1 & 2 & 1 & 2 & 0 & 1 & 1 & 2 \\
\hline Ireland & 6 & 4 & 0 & 3 & 4 & 2 & 7 & 1 & 2 & 2 \\
\hline Italy & 4 & 2 & 3 & 6 & 1 & 1 & 0 & 0 & 1 & 3 \\
\hline Luxembourg & 4 & 1 & 4 & 3 & 2 & 1 & 1 & 1 & 1 & 5 \\
\hline Netherlands & 5 & 4 & 3 & 3 & 2 & 2 & 0 & 2 & 1 & 8 \\
\hline Portugal & 3 & 4 & 1 & 3 & 1 & 2 & 1 & 1 & 1 & 3 \\
\hline Spain & 3 & 2 & 1 & 2 & 2 & 1 & 0 & 0 & 0 & 1 \\
\hline Sweden & 6 & 6 & 7 & 1 & 1 & 2 & 5 & 1 & 2 & 4 \\
\hline UK & 3 & 3 & 1 & 1 & 3 & 2 & 4 & 1 & 1 & 3 \\
\hline EU average* & 3 & 3 & 3 & 3 & 2 & 2 & 1 & 1 & 1 & 4 \\
\hline
\end{tabular}

* Weighted according to population size. 
Table 3a Percentage of EU subjects who are involved in various activities classified by demographics (sex, age and education level)

\begin{tabular}{|c|c|c|c|c|c|c|c|c|}
\hline & Walking & Gardening & Cycling & Keep fit & Swimming & Football & Dancing & Racquet sports \\
\hline \multicolumn{9}{|l|}{ Sex } \\
\hline Male & 28 & 18 & 18 & 8 & 9 & 12 & 4 & 6 \\
\hline Female & 33 & 17 & 16 & 12 & 11 & 1 & 7 & 3 \\
\hline \multicolumn{9}{|c|}{ Age group (years) } \\
\hline $15-34$ & 25 & 8 & 18 & 16 & 12 & 13 & 8 & 7 \\
\hline $35-54$ & 30 & 21 & 18 & 10 & 10 & 4 & 4 & 4 \\
\hline $55+$ & 40 & 27 & 14 & 4 & 7 & 0 & 3 & 1 \\
\hline \multicolumn{9}{|c|}{ Education level } \\
\hline Primary & 31 & 18 & 16 & 5 & 7 & 4 & 3 & 2 \\
\hline Secondary & 30 & 19 & 17 & 11 & 10 & 7 & 6 & 4 \\
\hline Tertiary & 34 & 15 & 19 & 17 & 16 & 8 & 7 & 9 \\
\hline
\end{tabular}

Table 3b Percentage of EU subjects who are involved in various activities classified by demographics (sex, age and education level)

\begin{tabular}{|c|c|c|c|c|c|c|c|c|c|c|}
\hline & $\begin{array}{l}\text { Team } \\
\text { sports }\end{array}$ & Fishing & $\begin{array}{l}\text { Winter } \\
\text { sports }\end{array}$ & Athletics & $\begin{array}{c}\text { Hill } \\
\text { walking }\end{array}$ & $\begin{array}{l}\text { Martial } \\
\text { arts }\end{array}$ & Golf & $\begin{array}{l}\text { Water } \\
\text { sports }\end{array}$ & $\begin{array}{l}\text { Equestrian } \\
\text { sports }\end{array}$ & Others \\
\hline \multicolumn{11}{|l|}{ Sex } \\
\hline Male & 5 & 6 & 4 & 3 & 2 & 3 & 2 & 1 & 1 & 4 \\
\hline Female & 2 & 1 & 2 & 2 & 1 & 1 & 0 & 0 & 1 & 4 \\
\hline \multicolumn{11}{|c|}{ Age groups (years) } \\
\hline $15-34$ & 7 & 3 & 4 & 4 & 2 & 3 & 1 & 1 & 2 & 3 \\
\hline $35-54$ & 2 & 3 & 3 & 2 & 2 & 1 & 1 & 1 & 1 & 4 \\
\hline $55+$ & 1 & 2 & 1 & 1 & 1 & 0 & 1 & 0 & 0 & 4 \\
\hline \multicolumn{11}{|c|}{ Education level } \\
\hline Primary & 2 & 3 & 1 & 1 & 1 & 1 & 0 & 0 & 0 & 4 \\
\hline Secondary & 4 & 4 & 3 & 3 & 2 & 2 & 1 & 1 & 1 & 4 \\
\hline Tertiary & 5 & 2 & 4 & 3 & 4 & 2 & 3 & 2 & 1 & 4 \\
\hline
\end{tabular}

At the European level the five activities with the highest level of participation include walking, gardening, cycling, keep fit and swimming (Table 2a). Walking is the first activity in most countries, with the exception of Denmark, Germany and the Netherlands in which gardening and cycling involve morepeople than any other activities. In Portugal, the number of participants in each activity was lower than the average EU figure, except for football, with $10 \%$ of participants. In general, in the EU, most other activities involve less people with the exception of hill walking practiced by $19 \%$ of Austrians, winter sports practiced by $17 \%$ of Finns and $14 \%$ of Austrians and fishing by $10 \%$ of Finns (Table 2).

Gender differences were observed in relation to several activities. In walking, keep fit, swimming and dancing there were higher levels of participation among women compared to men (Table 3). On the other hand, in football, other team sports, racquet sports, cycling and fishing there were more male than female participants. As age increased, the number of participants decreased for most activities, except in relation to walking and gardening. With increased education there were more participants in most activities, with the exception of gardening and fishing (Table 3).

\section{Time dedicated to physical activity}

In general, across the EU member states, there were similar patterns of time distribution dedicated to physical activity during 1 week, most Europeans falling into the two extremes of our classification: $31 \%$ not participating in any activity and 59\% spending more than 3.5 hours per week in one or more activities (Table 4).

Table 4 Percentage of subjects in each member state in the different categories of time dedicated to leisure-time physical activity (number of hours per week)

\begin{tabular}{lcccc}
\hline Country & None & $<1.5 \mathrm{~h}$ & $1.5-3.5 \mathrm{~h}$ & $>3.5 \mathrm{~h}$ \\
\hline Austria & 13 & 1 & 7 & 77 \\
Belgium & 38 & 2 & 9 & 50 \\
Denmark & 23 & 2 & 7 & 67 \\
Finland & 8 & 1 & 6 & 84 \\
France & 35 & 2 & 9 & 54 \\
Germany & 30 & 1 & 8 & 61 \\
Greece & 40 & 1 & 6 & 54 \\
Ireland & 13 & 1 & 6 & 80 \\
Italy & 38 & 3 & 8 & 52 \\
Luxembourg & 18 & 4 & 10 & 68 \\
Netherlands & 16 & 1 & 9 & 73 \\
Portugal & 60 & 3 & 7 & 30 \\
Spain & 37 & 3 & 11 & 49 \\
Sweden & 10 & 2 & 5 & 83 \\
UK & 23 & 1 & 9 & 67 \\
EU average & 31 & 2 & 8 & 59 \\
\hline
\end{tabular}

* Weighted according to population size. 
Table 5 Percentage of EU subjects in the different categories of time dedicated to leisure-time physical activity (number of hours per week) classified by demographics (sex, age and education level)

\begin{tabular}{lcccc}
\hline & None & $<1.5 \mathrm{~h}$ & $1.5-3.5 \mathrm{~h}$ & $>3.5 \mathrm{~h}$ \\
\hline Sex & & & & \\
$\quad$ Male & 28 & 2 & 7 & 64 \\
$\quad$ Female & 35 & 2 & 9 & 54 \\
Age group (years) & & & & \\
15-34 & 27 & 2 & 8 & 64 \\
35-54 & 33 & 2 & 8 & 57 \\
55+ & 36 & 2 & 8 & 54 \\
Education level & & & & \\
$\quad$ Primary & 41 & 2 & 9 & 48 \\
$\quad$ Secondary & 29 & 2 & 8 & 62 \\
$\quad$ Tertiary & 23 & 2 & 8 & 68 \\
\hline
\end{tabular}

It is worth noticing the homogeneity across the EU states, with only $1-4 \%$ of respondents participating for less than 1.5 hours weekly. An additional 8\% of Europeans, on average, participate in physical activity for 1.5-3.5 hours each week. However, most respondents participate in physical activity for more than 3.5 hours per week, with the Nordic countries being again those with the highest rates and Portugal the lowest (Table 4). In terms of non-participation in any physical activity, more countries were found to be below the EU average, with Finland, Sweden, Austria and Ireland having the lowest numbers of non-participants, while Spain, Italy, France, Belgium, Greece and Portugal were all above the EU average (Table 4).

Women were found to participate less and for shorter periods of time than men. It was also observed that with increased age, the proportion of older subjects participating for more than 3.5 hours decreased. On the other hand, subjects with higher education levels were more likely to participate in activities for longer periods of time than those with lower levels of education (Table 5).

Table 6 Percentage of subjects in each member state in the different categories of the indicator of daily activity levels

\begin{tabular}{lccc}
\hline Country & Reduced & Moderate & More than moderate \\
\hline Austria & 24 & 27 & 50 \\
Belgium & 26 & 26 & 49 \\
Denmark & 32 & 35 & 33 \\
Finland & 33 & 30 & 37 \\
France & 19 & 26 & 55 \\
Germany & 39 & 34 & 28 \\
Greece & 28 & 27 & 45 \\
Ireland & 20 & 25 & 54 \\
Italy & 21 & 28 & 52 \\
Luxembourg & 21 & 34 & 45 \\
Netherlands & 35 & 32 & 32 \\
Portugal & 24 & 29 & 47 \\
Spain & 22 & 25 & 53 \\
Sweden & 23 & 33 & 44 \\
UK & 34 & 32 & 34 \\
EU average & 28 & 30 & 42 \\
\hline
\end{tabular}

*Weighted according to population size.
Table 7 Percentage of EU subjects in the different categories of the indicator of daily activity levels classified by demographics (sex, age and education level)

\begin{tabular}{lccc}
\hline & Reduced & Moderate & More than moderate \\
\hline Sex & & & \\
$\quad$ Male & 29 & 29 & 42 \\
$\quad$ Female & 27 & 31 & 43 \\
Age group (years) & & & \\
15-34 & 27 & 27 & 45 \\
$35-54$ & 22 & 28 & 50 \\
$55+$ & 37 & 34 & 29 \\
Education level & & & \\
$\quad$ Primary & 29 & 32 & 39 \\
$\quad$ Secondary & 26 & 30 & 44 \\
$\quad$ Tertiary & 32 & 25 & 44 \\
\hline
\end{tabular}

\section{Indicator of daily activity}

When the indicator of daily activity (which excluded the contribution of engagement in specific activities) was calculated, $28 \%$ of Europeans were found to have a reduced activity level during the week at work and during leisure time, 30\% a moderate activity level and $42 \%$ a more than moderate level (Table 6). Most countries show increasing proportions of people from the lowest to the more active levels, with the exception of Denmark and the UK with a similar distribution across the three levels. On the other hand, Germany and the Netherlands show more people with a reduced level. Even the southern countries have around 50\% of their subjects in the group having a more than moderate activity level (Table 6).

Both genders showed similar distributions in their daily activity. Older subjects were more likely to fall in the reduced activity group, whereas the other two age groups had higher proportions in the more than moderate daily activity category. Education does not seem to have a marked effect as similar distributions were found across the three levels (Table 7).

When the time dedicated to physical activity was compared to the indicator of daily activity there was a slight tendency for those not involved in activities to also have a reduced activity level in their daily life. On the contrary, those with more than 3.5 hours of activity had a slight tendency to have a more than moderate daily activity level (Table 8).

Table 8 Percentage of EU subjects in the different categories of time dedicated to physical activity (number of hours per week) classified by indicator of daily activity level

\begin{tabular}{lcccc}
\hline $\begin{array}{l}\text { Indicator of daily } \\
\text { activity level }\end{array}$ & None & $<1.5 \mathrm{~h}$ & $1.5-3.5 \mathrm{~h}$ & $>3.5 \mathrm{~h}$ \\
\hline Reduced & 34 & 2 & 8 & 57 \\
Moderate & 32 & 2 & 8 & 59 \\
More than moderate & 29 & 2 & 9 & 60 \\
\hline
\end{tabular}




\section{Body mass index}

Only $48 \%$ of Europeans fell within the normal BMI range (class 2), 31\% were overweight and 10\% obese (Table 9). The highest proportions of overweight people were observed in Germany (35\%) and Greece (34\%), and the lowest in France (23\%). Around 11\% of subjects in the UK, Spain, Germany, Austria and Greece were obese. On average, 11\% of Europeans have a BMI below 20 but in France and Italy this proportion is higher, reaching $17 \%$ and $14 \%$, respectively (Table 9 ).

Many more women than men were found to have

Table 9 Percentage of subjects in each member state in the different BMI categories $\left(\mathrm{kg} \mathrm{m}^{-2}\right)$

\begin{tabular}{lcccc}
\hline Country & $1(\leqslant 19.9)$ & $2(20-24.9)$ & $3(25-29.9)$ & $4(\geqslant 30)$ \\
\hline Austria & 10 & 48 & 32 & 11 \\
Belgium & 12 & 48 & 31 & 9 \\
Denmark & 13 & 49 & 31 & 8 \\
Finland & 9 & 48 & 32 & 10 \\
France & 17 & 52 & 23 & 7 \\
Germany & 8 & 46 & 35 & 11 \\
Greece & 9 & 46 & 34 & 11 \\
Ireland & 10 & 50 & 31 & 8 \\
Italy & 14 & 49 & 30 & 7 \\
Luxembourg & 11 & 53 & 26 & 9 \\
Netherlands & 9 & 52 & 29 & 10 \\
Portugal & 8 & 50 & 33 & 9 \\
Spain & 9 & 47 & 33 & 11 \\
Sweden & 10 & 49 & 33 & 7 \\
UK & 11 & 48 & 30 & 11 \\
EU average* & 11 & 48 & 31 & 10 \\
\hline
\end{tabular}

${ }^{*}$ Weighted according to population size. a BMI below the normal range (17\% versus 6\%) whereas $37 \%$ of men and $25 \%$ of women were overweight (Table 10). As age increased, so did the proportion of overweight and obese subjects. Whereas the highest proportion of these underweight were younger subjects (20\%). With increasing education levels, the percentage of underweight and normal weight subjects increased. Conversely, the proportions of overweight and obese subjects increased with decreasing level of education (Table 10).

As BMI increases, the number of hours participating in any physical activity decreases, the obese subjects being those less involved in the various activities (Table 11). Overweight and obese subjects are more involved in gardening than any other subjects $(21.5 \%$ and $22 \%$, respectively). Subjects within the normal BMI range or who are overweight are more involved in cycling (18\% and 17\%, respectively) and the preferred activity of underweight subjects is keep fit (15\%) (data not shown).

In general there was no strong association between BMI categories and the indicator of daily activity but there was a tendency for subjects within the normal BMI range to fall in the more than moderate activity group and for the overweight and obese to fall within the reduced/moderate groups (Table 12).

\section{Discussion}

The benefits of physical activity range from the prevention of overweight and obesity to a number of

Table 10 Percentage of EU subjects in each BMI category $\left(\mathrm{kg} \mathrm{m}^{-2}\right)$ classified by demographics (sex, age and education level)

\begin{tabular}{lcccr}
\hline & $1(\leqslant 19.9)$ & $2(20-24.9)$ & $3(25-29.9)$ & $4(\geqslant 30)$ \\
\hline Sex & & & & \\
$\quad$ Male & 6 & 48 & 37 & 10 \\
$\quad$ Female & 17 & 48 & 25 & \\
Age group (years) & & & & 5 \\
$\quad$ 15-34 & 20 & 56 & 19 & 11 \\
35-54 & 8 & 47 & 34 & 15 \\
$55+$ & 5 & 39 & 42 & \\
Education level & & & & 14 \\
$\quad$ Primary & 6 & 40 & 40 & 8 \\
$\quad$ Secondary & 13 & 51 & 28 & 5 \\
$\quad$ Tertiary & 16 & 56 & 24 & \\
\hline
\end{tabular}

Table 11 Percentage of EU subjects in each BMI category $\left(\mathrm{kg} \mathrm{m}^{-2}\right)$ classified by the amount of time dedicated to physical activity (number of hours per week)

\begin{tabular}{lcccc}
\hline $\begin{array}{l}\text { Physical activity } \\
\text { time }(\mathrm{h})\end{array}$ & $1(\leqslant 19.9)$ & $2(20-24.9)$ & $3(25-29.9)$ & $4(\geqslant 30)$ \\
\hline None & 11 & 45 & 32 & 12 \\
$<1.5$ & 9 & 45 & 32 & 15 \\
$1.5-3.5$ & 11 & 46 & 34 & 9 \\
$>3.5$ & 12 & 51 & 29 & 8 \\
\hline
\end{tabular}




\begin{tabular}{|c|c|c|c|c|}
\hline $\begin{array}{l}\text { Indicator of daily } \\
\text { activity level }\end{array}$ & $1(\leqslant 19.9)$ & $2(20-24.9)$ & $3(25-29.9)$ & $4(\geqslant 30)$ \\
\hline Reduced & 11 & 47 & 31 & 11 \\
\hline Moderate & 11 & 46 & 32 & 11 \\
\hline More than moderate & 12 & 51 & 29 & 8 \\
\hline
\end{tabular}

other physiological and psychological benefits. It appears to improve health-related quality of life by enhancing physiological well-being and by improving physiological functioning in all populations ${ }^{4,5}$. However, the changes in technological societies that have occurred throughout this century contribute to a general decrease in physical activity both at work and in leisure time. Thus, changing our sedentary society into a more active one presents a major challenge to public health promoters.

In general, a high proportion of Europeans are involved in a variety of activities. However, wide interstate variations exist with the highest rates of participation being found in the nordic countries (e.g. Finland, 92\%) and the lowest in the southern ones (e.g. Portugal, 40\%). This may reflect not only different beliefs about physical activity and its benefits but also the existence or absence of programmes promoting physical activity and the conditions to practice it. In Finland many programmes are longstanding and have led to beliefs and behaviour changes ${ }^{13,14}$ whereas in Portugal physical activity promotion is relatively recent, confined to specific geographical areas and targeted at particular groups (e.g. sports for children in schools or in clubs).

In this survey, walking was the most frequently selected activity, though there were differences between EU countries, ranging from only $20 \%$ in Portugal to $68 \%$ in Finland. In contrast to these geographical differences there were no gender or education level differences in participation in walking, though it did increase with age. Unlike walking, more structured activities, such as keep fit, swimming, team and racquet sports, were praticed more by a higher proportion of younger and more highly educated subjects than by those who were older or with lower education levels. In general, the more active people tend to be young, male and with higher education levels. Activities such as walking, for instance, which do not require either special facilities or specific equipment may be considered promising and worth promoting to those not yet engaging in activities. As it combines efficacy in disease prevention with maximum adoption and maintenance, it seems easily attainable by almost all population groups, especially the overweight/obese, the older age groups and the less educated groups, as results from this survey seem to indicate.

The large interstate variation in participation levels for different activities indicates the scope to increase the rates in those countries who are currently less involved and also suggests that, in each country, physical activity promotion needs to take into account the most popular activities and the existence of an adequate environment to engage in physical exercise.

In terms of the amount of time devoted to different levels of activity, the EU is divided into two main and extreme groups: those not participating at all (31\%) and those with a weekly participation above 3.5 hours (59\%). Among these two groups, again, wide intercountry variation was found with the proportion of subjects not participating at all ranging from only $8 \%$ (Finland) to 60\% (Portugal), and the proportion of those participating for more than 3.5 hours ranging from 30\% (Portugal) to 84\% (Finland). In contrast, the two intermediate groups are more homogenous: $1-4 \%$ participate for up to 1.5 hours and $5-11 \%$ participate for between 1.5 and 3.5 hours per week. This indicates that most of those who are involved in some form of activity devote a substantial amount of time to their chosen activities, and moderate levels of activity in terms of the amount of time devoted to it are not common within the EU population. However, these levels of low to moderate physical activity should be encouraged, in particular among some groups (older, overweight/obese) as the recommendations suggest that levels of between 1.5 and 3.5 hours per week of aerobic activity is enough to have positive effects on aerobic capacity. Furthermore, some activity, even in several short bouts during the day, seems to be better than none $e^{5,15,16}$. Also, low- to moderate-intensity activity is more likely to be mantained than high-intensity activity and the establishment of self-regulatory skills like goal setting will help subjects to continue exercising ${ }^{16,17}$.

The results of this study also draw attention to the need to evaluate with precision the non-sport daily activities. Considering that differences in education and other sociodemographic variables may influence the subject's ability to recall daily activities, and the fact that this indicator of daily activity has not yet been validated, we stress the need to assess precisely 
the levels of activity at work and in leisure time as major differences were found across the EU. These activities make up large amounts of daily time and may influence health and well-being. However, such non-sport activities are not promoted during breaks in work time, or even at home. Another important aspect is an unconscious choice for inactivity as seen in the time spent sitting down in leisure time. Promoting more activity during this time is also needed as the indicator of daily activity suggests that those not engaged in physical activity also tend to be less active in their daily life. This calls for a reduction in the amount of leisure time spent in sedentary pursuits (watching TV, playing computer games, etc.)

This study confirms that being overweight and obese is a significant problem in the EU, especially as age increases. Even bearing in mind that self-reported weight and height may be unreliable indicators of body mass and that overweight/obese people tend to underestimate their weight, a certain degree of homogeneity in BMI categories was found across Europe, with more than $40 \%$ of Europeans being overweight or obese. This is in line with other assessments that have revealed that overweight/ obesity is a European public health problem ${ }^{18}$. Crosssectional data often reveal an inverse relationship between BMI and physical activity, indicating that the overweight and the obese are less active than their lean counterparts ${ }^{19-21}$. In this survey the overweight/ obese were also found to be less active, both in their daily occupations and in exercise, than normal/ underweight subjects. In particular, those with a lower level of education, older subjects and those who are less involved in physical activity may share a complexity of factors thereby putting their health at risk. Engaging in simple activities such as walking or gardening may help in reversing this situation as they may be easily integrated within the individual's schedule.

The other side of the problem is the important number of underweight subjects, specially in some countries (France 17\%, Italy 14\%). These are mainly young women who are highly educated, and regularly engage in physical activity. Despite being thin, 17\% of them see themselves as $\mathrm{fat}^{22}$. This raises concerns about eating disorders and unhealthily low body weight. Although in western societies the stigma of body fat pertains to both genders, pressures on women to be thin are stronger, contributing to the increasing problem of eating disorders, weight fluctuation and over-exercising ${ }^{23,24}$. This needs to be taken into account when choosing target groups for physical activity promotion.

Older women, and those women with lower education levels, are another group in need of increased physical activity. In general, they share a more reduced activity level with the overweight and they believe that they do not need to do more activity than they already do. In general, men have more leisure-time activities and were found to participate in all physical activities more than women who, on the other hand, have more domestic tasks ${ }^{25}$. Women may not be so involved in physical activity due to the feeling that in addition to working outside the home, and being the ones exclusively responsible for most household tasks, they are getting more than enough activity. In fact, the care of children/relatives and most household chores are important sources of occupation for women. At the end of the day they may feel too tired to be involved in physical activity, they may simply lack the time, or not find compatible timetables for engaging in other activities. This group is potentially encourageable, so it seems important to inform them, in relation to their daily routines, of the differences and benefits of physical activity, namely for stress management and to socialize. Again simple, less structured activities such as walking, gardening and dancing could be useful ways to increase this group's activity levels.

These results show that with regard to physical activity and body weight, Europeans are divided into two extremes: (1) those not engaging in any physical activity and the overweight/obese, and (2) those practising an activity for more than 3.5 hours per week and the underweight. These disparities are not only observed among the countries (e.g. the Nordic versus the southern ones) but also within each country. Several risk groups related to physical activity emerged from this survey, including women, less educated, older subjects, the overweight/obese and the underweight.

Programmes to promote exercise need to be tailored to the different groups identified in each country/ region in order to decrease the gap between the non-active and the most active. Based on a detailed analysis of this project, each member state should formulate policies of health promotion, leading to a coordination of efforts between the public and the private sectors, thus creating the right environment for the adoption and adherence of non-participants and for the maintenance of those already engaged in physical activity.

\section{References}

1 Bouchard C, Shephard RJ, Stephens T. Physical fitness and health: the model and key concepts. In: Bouchard C, Shephard RJ, Stephens T, eds. Physical Activity, Fitness and Health: International Proceedings and Consensus Statement. Champain, IL: Human Kinetics, 1994; 77-89.

2 Åstrand PO. Physical activity and fitness: evolutionary perspective and trends for the future. In: Bouchard C, Shephard RJ, Stephens T, eds. Physical Activity, Fitness and 
Health: International Proceedings and Consensus Statement. Champain, IL: Human Kinetics, 1994; 98-106.

3 US Department of Health and Human Services. Guidelines for School and Community Programs for Lifelong Physical Activity Among Young People. Morbidity and Mortality Weekly Report. Atlanta: Public Health Service, Centers for Disease Control and Prevention, 1997.

4 US Department of Health and Human Services. Physical Activity and Health: a Report of the Surgeon General. Atlanta: Centers for Disease Control and Prevention, National Center for Chronic Disease Prevention and Health Promotion, 1996.

5 Pate R, Pratt M, Blair SN, et al. Physical activity and public health: a recommendation from the Centers for Disease Control and Prevention and the American College of Sports Medicine. JAMA 1995; 273: 402-7.

6 Sardinha L, Teixeira P. Physical activity and public health: a physical education perspective. Motricidade Humana. Portuguese J. Hum. Perform. Stud. 1995; 11: 3-16.

7 Haskell W. Dose-response issues from a biological perspective. In: Bouchard C, Shephard RJ, Stephens T, eds. Physical Activity, Fitness and Health: International Proceedings and Consensus Statement. Champain, IL: Human Kinetics, 1994; 1030-9.

8 World Cancer Research Fund, American Institute for Cancer Research. Food, Nutrition and the Prevention of Cancer: $a$ Global Perspective. Washington DC: AICR/WCRF, 1997.

9 Wilmore J. Increasing physical activity: alterations in body mass and composition. Am. J. Clin. Nutr. 1996; 63: S456-60.

10 ILSI Europe. Healthy Lifestyles, Nutrition and Physical Activity. ILSI Europe Concise Monograph Series. Belgium: ILSI Europe, 1998.

11 Kearney JM, Kearney MJ, McElhone S, Gibney MJ. Methods used to conduct the pan-European Union survey on consumer attitudes to physical activity, body weight and health. Public Health Nutr. 1999; 2: 79-86.

12 Garrow JS. Treat Obesity Seriously. Edinburgh: Churchill Livingstone, 1981.

13 Lahelma E, Rahkonen O, Berg MA, et al. Changes in health status and health behaviour among Finnish adults 19781993. Scand. J. Work Environ. Health 1997; 23: 85-90.
14 Steptoe A, Wardle J, Fuller R, et al. Leisure-time physical exercise: prevalence, attitudinal correlates and behavioural correlates among young Europeans from 21 countries. Prev. Med. 1997; 26: 845-54.

15 Blair SN, Connelly J. How much physical activity should we do? The case for moderate amounts and intensities of physical activity. Res. Q. Exerc. Sport 1996; 67: 193-205.

16 Pollock ML. Prescribing exercise for fitness and adherence. In: Dishman RK, ed. Exercise Adherence. Champaign, IL: Human Kinetics, 1988; 259-77.

17 Dishman RK. Compliance/adherence in health related exercise. Health Psychol. 1982; 1: 237-67.

18 Epstein FH, Higgins M. Epidemiology of obesity. In: Björntrop P, Brudoff BN, eds. Obesity. JB Lippincott, 1992; 330-42.

19 Schulz LO, Schoeller DA. A compilation of total daily energy expenditures and body weights in healthy adults. Am. J. Clin. Nutr. 1994; 60; 676-81.

20 Davies PS, Gregory J, White A. Physical activity and body fatness in pre-school children. Int. J. Obes. Relat. Metab. Disord. 1995; 19: 6-10.

21 Westerterp KR, Goran MI. Relationship between physical activity related energy expenditure and body composition: gender difference. Int. J. Obes. Relat. Metab. Disord. 1997; 21: $184-8$.

22 McElhone S, Kearney JM, Giachetti I, Zunft F, Martínez JA. Body image perception in relation to recent weight changes and strategies for weight loss in a nationally representative sample in the European Union. Public Health Nutr. 1999; 2 143-151.

23 Czajka D, Parham E. Fear of fat: attitudes towards obesity. Nutr. Today 1990; 25: 26-32.

24 Bellisle F, Monneuse MO, Steptoe A, Wardle J. Weight concerns and eating patterns: a survey of university students in Europe. Int. J. Obes. 1995; 19: 723-30.

25 Dannenberg AL, Keller JB, Wilson PWF, Castelli WP. Leisure time physical activity in the Framingham offspring study. Description, seasonal variation, and risk factors correlates. Am. J. Epidemiol. 1989; 129: 76-88. 


\section{A leading international journal publishing authoritative, timely and in-depth reviews...} Nutrition Research Reviews

General Editor JM Forbes (UK)

Editors

DJ Millward (UK)

HJ Powers (UK)

DI Thurnham (UK)

P Yaqoob (UK)

International Editors

J Black (Australia)

L Hambraeus (Sweden)

JOkumura (Japan)

NW Solomons (Guatemala)

CM Weaver (USA)

\section{(1) $C A B \mid$ Publishing}

publishes Nutrition Research Reviews on behalf of The Nutrition Society

\section{Contributions by international} experts:

- advance new concepts

- encourage fresh thinking

- highlight timely reports on important techniques and methods in experimental work

- provide thorough overviews on specific subject areas

- promote scientific communications on new ideas

Reviews of large-scale, international projects and surveys such as the EURESTA project feature prominently in Nutrition Research Reviews.

Leading nutritionists look back on a lifetime of involvement in important developments in nutrition research.

Forthcoming papers include:

- Homocysteine as a risk factor for cardiovascular and related disease: nutritional implications

- Irritable bowel syndrome: the interactions of diet and stress

- Perspectives on ruminant nutrition and metabolism

- Lipids and infant formulas

1999, Volume 12

Bi-annual publication (June and December)

ISSN: 09544224

$£ 100.00$ (US\$180.00 Americas only)

To order your 1999 subscription to this important journal contact:

CABI Publishing

$\mathrm{CAB}$ International

Wallingford, Oxon, OX10 8DE, UK

Tel: +44 (0) 1491832111

Fax: +44 (0) 1491829292

Email: publishing@cabi.org

CABI Publishing

$\mathrm{CAB}$ International

10 East 40th Street, Suite 3203,

New York, NY 10016, USA

Tel: +1 (212) 4817018

Toll-free: 18005284841

Fax: +1 (212) 6867993

Email: cabi-nao@cabi.org 